\title{
Nanoparticles for hematologic diseases detection and treatment
}

\author{
Tania Limongi*, Francesca Susa and Valentina Cauda \\ Department of Applied Science and Technology, Politecnico di Torino, Corso Duca degli Abruzzi 24, 10129 Turin, Italy
}

\begin{abstract}
Nanotechnology, as an interdisciplinary science, combines engineering, physics, material sciences, and chemistry with the biomedicine knowhow, trying the management of a wide range of diseases. Nanoparticle-based devices holding tumor imaging, targeting and therapy capabilities are formerly under study. Since conventional hematological therapies are sometimes defined by reduced selectivity, low therapeutic efficacy and many side effects, in this review we discuss the potential advantages of the NPs' use in alternative/combined strategies. In the introduction the basic notion of nanomedicine and nanoparticles' classification are described, while in the main text nanodiagnostics, nanotherapeutics and theranostics solutions coming out from the use of a wide-ranging NPs availability are listed and discussed.
\end{abstract}

\section{Nanomedicine and Nanoparticles}

The word "nanotechnology" generally states the production of new tools with nanometric dimensions [1]. Most of the nanotechnology success relies on the possibility to adapt the structures and the design of a wide range of materials at the nanoscale to add or tune specific properties, thus significantly magnifying the materials science toolkit.

Nanotechnology is demonstrating its great potential in healthcare for theranostics, preventive applications and medical-designed novelties that are referred to as "nanomedicine" by the USA National Institutes of Health [2]. More in details, the nanomedicine research includes in vitro and in vivo medical diagnostics, nanopharmaceuticals and regenerative medicine applications [3-8].

Nanoparticles (NPs) represent one of the most successful solution that nanomedicine proposes to solve huge biomedical questions. With their size ranging from 1 to $100 \mathrm{~nm}$, NPs are characterized by a considerable surface area-to-volume ratio. As described in [9] for diagnosis, therapy, and drug delivery applications, it is essential the obtainment of monodisperse NP preparations to avoid side effects coming out from aggregation phenomena. Starting from nanomaterials composition, tuning particles size, shape and functionalization states, it is possible enhance their in vitro and in vivo biodistribution, drug delivery and/or targeting capabilities.

Regarding their chemical composition, NPs can be distinguished into three main groups: carbon-based, organic and inorganic materials.

\section{Carbon-Based Nanoparticles}

The first group (Figures 1A and 1B) includes carbon nanotubes and fullerenes $[10,11]$.

Fullerenes, water insoluble sphere containing 60 carbon atoms, represent the third allotophic form of carbon with respect to diamond and graphite. Fullerene derivatives have been successfully used for different diagnostics and therapeutics applications, many groups reported the use of these carbon allotropes for medical imaging and drug delivery purposes together with photodynamic, hyperthermia and acoustic wave assisted therapies $[12,13]$.

Carbon Nano Tubes (CNTs) were classified into single-walled carbon nanotube (SWCNT) and multi-walled carbon nanotube (MWCNT) since they can be constituted by rolling up respectively one or more graphitic sheets. CNTs are applied in a wide range of biomedical applications as tissue engineering scaffold, biosensors and as labelling, imaging, drug delivery and therapeutic agents [14,15].

\section{Organic Nanoparticles}

Concerning organic nanoparticles, we mainly refer to polymeric nanoparticles (PNPs), liposomes, and extracellular vesicles (EVs) (Figures 1C and 1D).

PNPs can be made from natural or synthetic polymers and thanks to their biocompatibility and biodegradability represent one of the most considered organic approaches for solve some nanomedicine challenges [16]. They can be produced by nanoprecipitation, dialysis methods, supercritical fluid technology, and two-step emulsification methods (emulsification-solvent diffusion, emulsification-solvent evaporation and emulsification-reverse salting-out). Their size and solubility can be tuned during the manufacturing process [17].

Liposomes are sphere-shaped vesicles made up of a lipid bilayer. They can be prepared starting from cholesterols, phospholipids, surfactants and proteins [18]. Liposomes can be synthetized by using different methods such as sonication, extrusion and the Mozafari method [19]. They can be considered as delivery systems able to carry

${ }^{\star}$ Correspondence to: Tania Limongi, Department of Applied Science and Technology, Politecnico di Torino, Corso Duca degli Abruzzi 24, 10129 Turin, Italy, E-mail: tania.limongi@polito.it

Key words: nanomedicine, nanoparticles, theranostics, leukemia, lymphoma, blood diseases

Received: May 27, 2019; Accepted: June 25, 2019; Published: June 28, 2019 

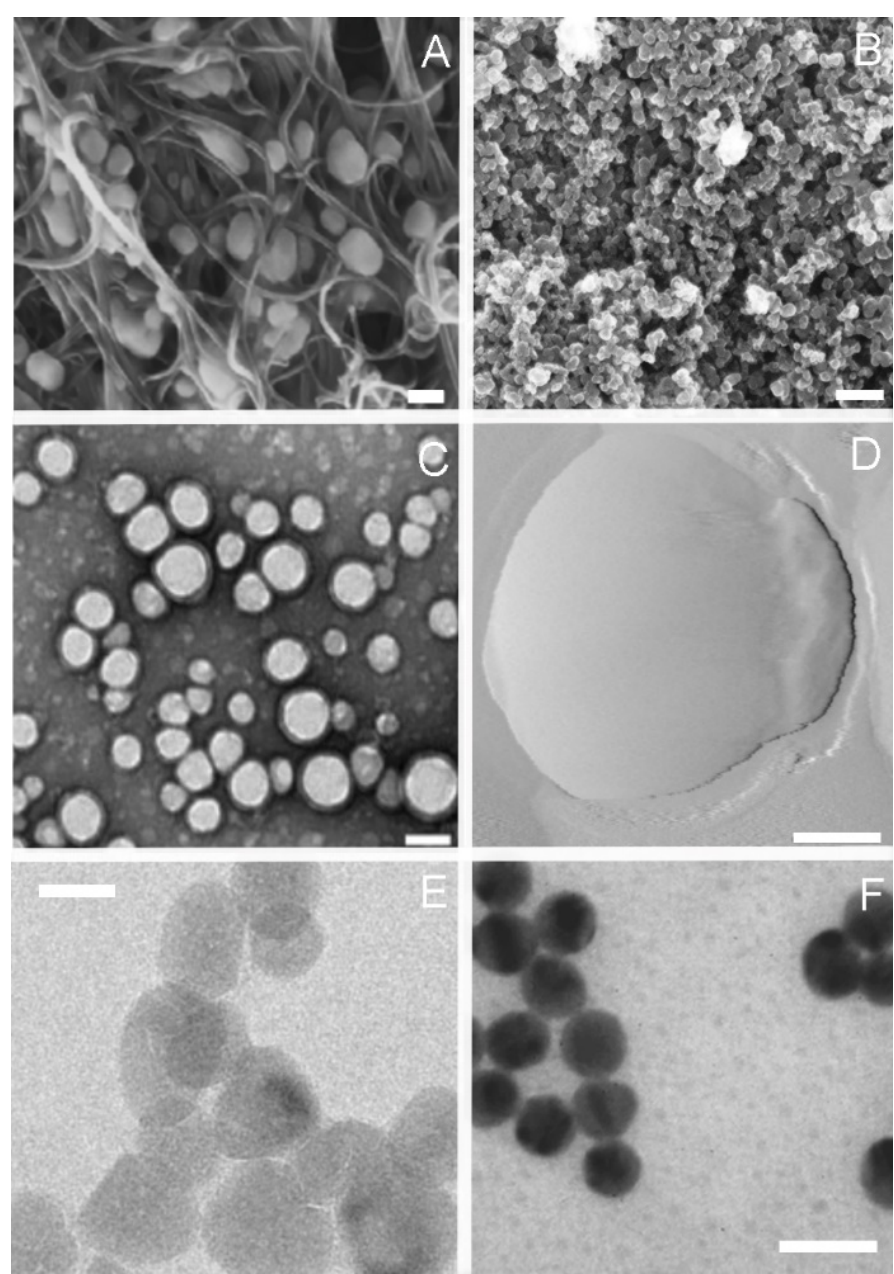

Figure 1. High resolution images of the main category of nanoparticles: carbon based (A,B), organic (C,D) and inorganic (E,F). (A) Scanning electron microscopy (SEM) of H5N2 AIV virions trapped inside the aligned nitrogen-containing multiwalled carbon nanotubes, scale bar $100 \mathrm{~nm}$, adapted from [32]. (B) Field emission scanning electron microscopy images of carbon nanoparticles, scale bar $200 \mathrm{~nm}$, adapted from [33]. (C) Transmission electron microscopy (TEM) image of PLGA nanoparticles, scale bar $100 \mathrm{~nm}$, adapted from [34]. (D) Atomic force microscopy (AFM) image of a liposome, scale bar $50 \mathrm{~nm}$, adapted from [35]. (E) TEM image of pristine $\mathrm{ZnO}$ nanoparticles, scale bar $20 \mathrm{~nm}$, adapted from [31]. (F) TEM image of gold NPs synthesized by sodium citrate, scale bar $20 \mathrm{~nm}$, adapted from [36]

both hydrophilic and hydrophobic drugs and molecules in their core, but are largely used for include also specific target biomolecules and other nanomaterials [20-22].

Regarding the extracellular vesicles (EVs) application in the biomedical contest, one of the most applied EVs categories is undoubtedly the nanosized exosomes $(70-150 \mathrm{~nm})$. They are released by all cell types, fine-tuning physiological and pathophysiological intercellular statements [23]. At present, exosome-like nanoparticles, naturally or synthetically obtained, represent some of the most capable, biocompatible, and therapeutic agents [9,22,24,25]. An European network of experts, the European Network on Microvesicles and Exosomes in Health and Disease (ME-HAD), reveals the open-ended capability of nanosized EVs for nanotheranostic investigations and applications [26].

\section{Inorganic Nanoparticles}

The inorganic nanoparticles category includes Quantum Dots (QDs), Metallic (MNPs) and Metal Oxide (MONPs) Nanoparticles (Figures $1 \mathrm{E}$ and $1 \mathrm{~F}$ ).
QDs are semiconductor materials consisting of a core overcoated with a shell that is usually conjugated to peptides, proteins, polysaccharides and other biomolecules to prevent the leakage of the toxic-heavy metals and increase the overall NP stability in biological fluids. These kind of nanoparticles are the most used in bioimaging and biosensing strategies: gold quantum dots (GQDs), indium-phosphate (InP), cadmium-selenium (CdSe), indium-arsenate (InAs) cadmiumtellurium $(\mathrm{CdTe})$ can be differently applied for real time cell tagging and cellular apoptosis recognition [20].

MNPs comprise magnetic and precious metals: MNPs such as Palladium (PdNPs), silver (AgNPs), gold (AuNPs), and copper (CuNPs) unveiled wide applicability as theranostics agents while magnetic ones exhibiting high stability in hypoxic tumor conditions and are successfully applied as contrast imaging and bio-sensing agents [27].

Biocompatible MONPs such as ceria $\left(\mathrm{CeO}_{2}\right)$, mesoporous silica nanoparticles (MSNs), iron oxide $\left(\mathrm{Fe}_{3} \mathrm{O}_{4}\right)$, zirconia $\left(\mathrm{ZrO}_{2}\right)$, zinc oxide $(\mathrm{ZnO})$ and titania $\left(\mathrm{TiO}_{2}\right)$ show high chemical stability, antioxidant and catalytic actions that make them right for medical implants, drug delivery and bioimaging applications [22,28-31].

\section{Nanoparticles and Hematopathology}

In order to assess data about the topic 'blood nanoparticles', in the April of 2019 we conducted a literature search, using the Thomson Reuters Web of Science research portal. Results showed 16,398 records that were visualized with the tree map style selecting 25 as number of results, sorting data by read count and setting the minimum record count to 285 .

The result (Figure 2) highlighted how wild and transversal is the literature that can relate to this type of research and it clearly shows how the scientific production is centred on nanotechological, pharmacological and chemical aspects.

In this paper we review how nanotechnology and more in details how nanoparticles could support and improve existing methods for early stages hematological diseases' diagnosis and treatment, reducing side effects, relapses and costs.

Hematopathology studies the diseases related to blood, lymph nodes and bone marrow and, in this contest, nanoparticles-assisted nanomedicine can support researchers, physicians and clinicians providing complementary and/or alternative solutions to traditional diagnostic and therapeutic methods by providing effective and personalized solutions.

Considering that anemia, hemophilia, bleeding disorders and blood cancers as lymphoma, leukemia, and myeloma are just some of the many hematological pathologies, to emphasize the technological aspect of the discussion, in the next sections the three most broadly used NPs' applications in nanomedicine will be presented: diagnostics, therapeutics and theranostics.

\section{Nanoparticle-Based diagnosis}

Nanoscale diagnostic tools for early stage detection of cancer cells received a considerable attention in the recent years, in order to develop efficient methods able to isolate Circulating Tumor Cells (CTCs) from complex biological fluids.

In this contest, lymphoma cells present different non-glycosylated antigens on their surface. In particular, the CD20 antigen plays a critical role in the $\mathrm{B}$ lymphocytes activation and differentiation processes. The overexpression of this antigen on tumoral B cells made it a valid 


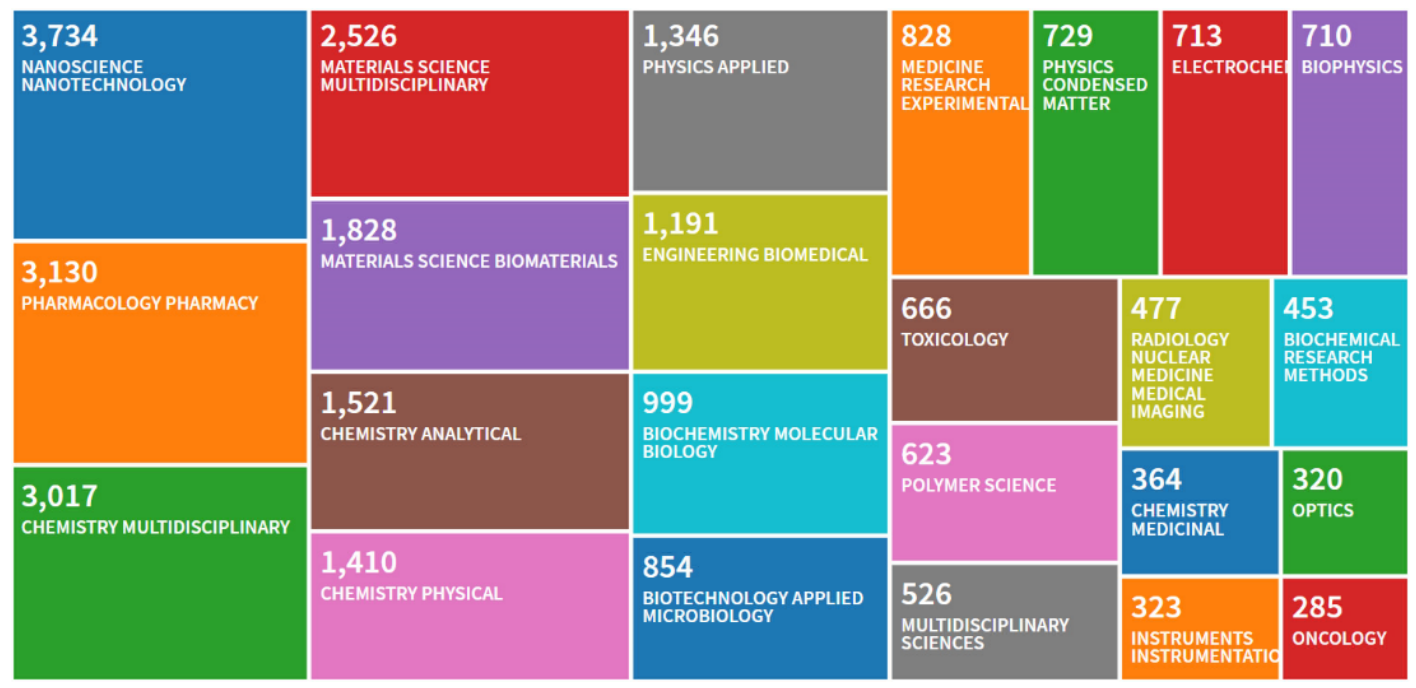

Figure 2. Thomson Reuters Web of Science research about the topic 'blood nanoparticles', made in April of 2019

target to successfully isolate CTCs in blood and other human fluids. Many detection methods are based on active targeting moieties, such as ligands and monoclonal antibodies. In particular, anti-CD20, e.g. Rituximab, directed against CD20 antigen, associated with different types of nanoparticles, i.e. QDs or magnetic nanoparticles, aim to isolate lymphoma cells exploiting the high affinity between antigen and antibody.

Shariatifar, et al. proposed a new tool for the detection of nonHodgkin lymphoma: Rituximab conjugated QDs bind specifically to tumor cells, allowing their detection through flow cytometry. Results display a higher sensitivity and specificity compared with immunohistochemistry, which is the current gold standard test [37].

QDs can be also conjugated with Sgc8c aptamer for an effective diagnosis of leukemia at the early stage by imaging tumor cells in vitro or in vivo [38].

Magnetic NPs characterized by having a high biocompatibility, stability, surface-to-volume ratio, binding-capacity and specificity were also successfully conjugated with anti-CD20 antibody to isolate lymphoma cells from biological fluids with an efficiency above the $95 \%$ [39]. At the same time, once functionalized with hyaluronic acids, they bound specifically to CD44 receptors, overexpressed in many types of leukemia and seized cancer cells from plasma samples. The subsequent analysis of the changes in mass loading, performed with a quartz crystal microbalance, detected the presence of tumor cells with high sensitivity, giving a feedback on cells' condition and on drugs' response [40].

CTC can also be detected with a customized device (biosensor), composed by a biological receptor and a physicochemical detector. They offer ease, quick and high sensitivity and specificity measurements of complex biological samples, in a very cost-effective process.

AuNPs have attracted attention as probes in biological detection for their biocompatibility, surface-to-volume ratio, ease of synthesis, surface functionalization and unique properties, among which the most important is their localized surface plasmon resonance (LSPR). AuNPs functionalized with thiolate oligonucleotides (Au-nanoprobes) can be used for the detection of bioanalytes, such as ions, proteins or target DNA at a lower cost comparing to traditional methods. The detection is carried out exploiting the LSPR, according to which their intense color changes together with the modification of the dielectric medium. Au-nanoprobes are efficiently applied to the direct detection of the molecular hallmark of chronic myeloid leukemia, BCR-ABL fusion transcripts, allowing the discrimination between the most frequent isoforms of this genetic abnormality, e13a2 and e14a2 [41]. Another sensor for the recognition of BCR-ABL is the BioCode Aunanobeacon which is constituted by AuNPs functionalized with hairpin shape strand DNAs with a fluorophore on the extremity. Due to their LSPR, AuNPs may act as dark quencher on the single strands' fluorophores. In absence of target, the hairpin remains in the close conformation keeping the fluorophore near the AuNP, which quenches the fluorescence. If there is a bind between the hairpin and its target, instead, the hairpin opens and the distance from the AuNP allows the detection of the fluorescence [42]. Mazloum-Ardakani, et al. created a biosensor for acute lymphoblastic leukemia (ALL) early detection. By combining graphene sheets and an electrosynthesized conductive polymer, poly(cathecol), a high electrically conductive surface was realized and AuNPs were deposited on it in order to use their affinity with thiol-modified DNA to immobilize the target DNA [43].

AuNPs-based biosensors can be used also for the detection of specific factor of the coagulation cascade: thrombin-binding aptamerconjugated AuNPs can detect thrombin [44,45], while peptidefunctionalized AuNPs the factor XIII activity, exploiting the LSPR of NPs [46].

Graphene sheets, combined in different ways with aptamers, are also successfully used for the detection of blood cancer cells. Aptamers are artificial single-stranded oligonucleotides, having great affinity and selectivity with their targets, i.e. cells, proteins, drugs or small molecules, lower immunogenicity and toxicity, higher chemical and thermal stability and smaller dimension compared with antibodies. They can be used conjugated to nanoparticles for the detection of specific cancer cells, for example linked to carbon QDs coated with zinc oxide nanospheres [47] or to quantum dots coated with chitosan [48]. Graphene sheets are directly functionalized with $\mathrm{Sgc} 8 \mathrm{c}$ and ATP aptamers [49] or with AuNPs conjugated with Sgc8c aptamer [50] to establish a bond with protein tyrosine kinase 7 , overexpressed in T-cell of ALL. Sgc8c aptamer can be also used in combination with fluorescent mesoporous silica nanoparticles to identify leukemia cells through fluorescence microscopy [51] or with silver-enhanced AuNPs which selectively isolate and immobilize leukemia cells on a quartz 
crystal microbalance sensor surface to detect real-time changes in the resonant frequency [52].

A portable sensor for a rapid analysis and diagnosis of acute myeloid leukemia was developed by using Surface Enhanced Raman Scattering (SERS). Hollow core photonic crystal fibers are integrated with silver NPs in order to enhance the weak Raman signal of cancerous cells even at very low cells counts up to 300 cells/ml [53]. SERS AuNPs were also used to facilitate the detection of surface proteins such as CD45, CD19, CD20 of leukemia and lymphoma cells [54].

The diagnosis of multiple myeloma involves the detection of the Bence-Jones protein in serum. A complementary exam is the detection of the protein in urine, however the current analyses, e.g. immunoelectrophoresis, immunonephelometry and heat precipitation, are time consuming, have low sensitivity, and provide inaccurate results. Long, et al. proposed a new approach which is more rapid, sensitive and economical if compared to these current methods. They used macroporous ordered silica foams to enrich proteins in urine which are then analysed with matrix-assisted laser desorption/ionization timeof-flight mass spectrometry, to detect the presence of the Bence-Jones protein [55].

\section{Nanoparticle-based therapy}

Many papers reported how MNPs' and MONPs' chemical-physical properties affect cancer cells viability. More in details silver NPs [56-59] and selenium NPs [60] are able to induce cells apoptosis on lymphoma cells in a dose dependent manner. Copper and cobalt oxide NPs display a selective cytotoxicity against hematological cancers cells through ROS generation or influencing p53 tumor suppressor gene activity [61,62].

Shahriari, et al. reported that L-asparaginase functionalized AuNPs are better internalized into leukemia T-cells than bare ones resulting more susceptible to localized hypertermia treatment [63].

Iron oxide NPs can enter B-cell lymphoma and multiple myeloma cells through phagocytosis and electrostatic interaction inducing cells autophagy and death. This induction of cells autophagy can be further non-invasively tuned by an external magnetic field [64] or by the addition of a chemotherapeutic agent, like bortezomib with gambogic acid [65].

Photodynamic therapy (PDT) is a non-invasive cancer treatment that is still under study but has shown great results. After the accumulation of a phosensitizer agent in the tumor, the diseased region is illuminated, usually with a laser source, and the photosensitizer transfer energy to molecular oxygen in order to generate ROS. $\mathrm{ZnO}$ NPs can act as photosensitizer [66] and their effects can be enhanced by the addition of chemotherapeutic agents, such as daunorubicin [67] or with other elements, such as manganese [68] to produce singlet oxygen which acts specifically against leukemic cells, without damaging healthy cells.

Metal NPs are promising nanocarriers for anticancer drugs, proteins or nucleic acids, thanks to their small size, biocompatibility and capacity to protect and deliver high payload of drugs selectively to the tumor by active or passive targeting methods.

AuNPs can deliver molecules with limited clearance, such siRNA [69], oligonucleotides that silence the BCR-ABL1 gene [70] or CpG and ovalbumin antigens that activate dT-cells reducing the tumor growth [71]. They can also be functionalized with anticancer drugs, such as 6-mercaptopurine [72], fludarabine phosphate [73], AS1411 [74] or dasatinib, a tyrosine kinase inhibitor, to reduce the effective dose [75].
Other chemotherapeutics can be loaded on different types of MNPs to improve their circulation time and the uptake by cancer cells, reducing side effects toxicity. For example, magnetic nanoparticles of magnetite can be coated with daunorubicin [76] or magnetite and silica with cytarabine [77], doxorubicin can be loaded on cadmium telluride QDs conjugated with PEG in order to also regulate the release in a $\mathrm{pH}$ depedent manner [78]. Iron oxide NPs combined with paclitaxel and anti-ABCG2 monoclonal antibodies improve the therapeutic effect of the drug and reduce multiple myeloma progression [79].

Iron or iron-based NPs are successfully used for the treatment of a non-cancerous blood disease like anemia. It is commonly treated by oral administration of ferrous sulfate supplements, but only a small part is absorbed in the upper intestinal tract and the remaining reaches the low tract where reacts with hydrogen peroxide and superoxide producing free radicals and unfavourable effects. The reduction of the size of iron to the nanometric scale, increases its bioavailability and gastrointestinal absorption [80]. Further coating such as lipids $[81,82]$, folic acid and chitosan [83] resulted to improve iron-based NPs stability and NPs inclusion in a bacteria, i.e. Lactobacillus fermentum, increased their efficiency [84]. In haemophilia treatment, Iron oxide NPs can be also coupled with factor VIIa for optimize its delivery [85].

MNPs can be applied also to coagulation disorders treatments: iron-derived NPs, such as magnetite, can be used as haemostatic agents. Magnetite matrix NPs, entrapping thrombin, are applied for a noninvasive treatment of internal bleeding: they are injected directly in the bloodstream, guided through an external magnetic field to the site of bleeding, where fibrinogen is injected to accelerate the coagulation process and the combination with thrombin-entrapped NPs stops the bleeding [86]. In contrast, some NPs can be used as anticoagulant agent: AuNPs coated with chitosan [87], the combination of AuNPs with thrombin binding aptamer produces nanoconstructs that interact with thrombin, inhibiting its activity, in a photo-controllable manner $[88,89]$. Zinc oxide NPs reduce the amount of thrombin and coagulation factors and prolong the time of thromboplastin and prothrombin [89]. Silver NPs, bare $[90,91]$ or coated with chitosan [92], shown a high thrombolitic potential.

MSNs, entrapping the drug inside their pores efficiently deliver chemotherapeutics to cancer cells. Daunorubicin was encapsulated in mesoporous silica NPs functionalized with the B220 antibody to actively and selectively target acute leukemia cells [93]. Once encapsulated inside the pore, drugs have to be retained in the pore through stimuli-responsive coating that can act as a sealant and under specific condition slowly release the payloads. For example, a peptide responsive to the bind with a specific receptor overexpressed by tumors [94], pH-responsive PEG telomerase responsive oligonucleotide sequences [95], biotin-avidin and pepsin enzyme cap [96] or adenosine triphosphate and calcium carbonate [97] seal the pores and MSNs release their cargoes only in presence of specific condition typical of the different types of tumors, causing enhanced apoptosis and higher drug's uptake. MSNs pores can be also sealed with lipid membranes creating a nanoconstruct called "protocell" [98] and the surface can be functionalized in different ways, for example by PEG binding, or targeting ligands [99].

MSNs can be employed as haemoglobin-based oxygen: exploiting the affinity between haemoglobin and MSNs, haemoglobin can be loaded inside the pores and replace the function of defective erythrocytes delivering oxygen to cells and tissues [100]. To control the release of haemoglobin MSNs can be coated with liposomes [101] while, 
for the controlled release of anticoagulant drugs, MSNs can be loaded with heparin. Once loaded with thrombin-specific cleavage sites and capped with a thrombin-sensitive peptide [102], MSNs can release the drugs to slow the coagulation cascade or if conjugated with thrombin binding aptamer and coated with a streptavidin cap, can be used for a reversible inhibition of thrombin activity toward fibrinogen [103]. MSNs were also covalently coated with heparin showing prominent anti-thrombogenic effects in whole blood from patient donors [104].

Among the many application of polymeric NPs in therapeutics, Poly(lactic-co-glycolic) acid (PLGA), as biodegradable polymer approved by FDA, is recognised as a valid drug delivery vehicle.

Curcumin, a natural hydrophobic yellow pigment with anticancer and anti-inflammatory properties, has low aqueous solubility and bioavailability so its drug delivery capability is enhanced by PLGA NPs incapsulation $[105,106]$. The same solution is used to deliver the antisense peptide nucleic acid that inhibits miR-155 expression to lymphoma cells: the withdrawal of this microRNA results in a rapid regression of the disease [107].

Barasertib or AZD2811 is a potent and selective Aurora B kinase inhibitor that has a pivotal role in inducing the chromosomes alignment during mitosis and controlling the cytokinesis, thus its inhibition induces polyploidization and cell death. The drug is encapsulated in polymeric nanoparticles called Accurine, composed of poly-D,L-lactide and poly(ethylen glycol). This drug delivery system allows a scheduling of weekly (or longer periods) administrations, thanks to the high dose delivered to the tumor that increases the durability of the response and decreases the toxic side effects $[108,109]$.

To overcome some of the limitations of standard anticancer drugs, they can be encapsulated inside biodegradable polymeric NPs which guarantees the delivery of the drug to the target site and a continuous and controlled release. Chlorambucil and hydroxychloroquine [110112] or doxorubicin [113] are loaded inside biodegradable polymeric NPs and are functionalized with anti-CD20 or anti-CD19 antibodies to specifically target different neoplastic B-cells. Idarubicin, an anthracycline antibiotic approved by FDA analogue to daunorubicin, can be encapsulated in methoxy poly(ethylene glycol)-b-poly(l-lactideco-glycolide) nanoparticles [114].

A special reference needs to be made to nanogels that are colloidal hydrogel particles composed by three-dimensional crosslinked hydrophilic polymers networks. They are used for the delivery of hydrophilic large molecules, with the aim to protect drugs from degradation, and their surface can be functionalized to improve the blood circulation and the cellular uptake. Their drug delivery properties are based on the hydrogels' capacity of swelling in aqueous environment instead of dissolving. Nanogels of linear thiolated poly(glycidol), modified with peptides sensitive to redox environment, loaded with the tumor suppressor miR-34a and a trans activator for transcription provide an effective tool for the treatment of multiple myeloma [115]. Other kinds of nanogels insert methotrexate in chitosan nanoparticles for intranasal administration in a central nervous system lymphoma [116].

Biodegradable polymers such as PCL or PLGA can be loaded with heparin [117], while chitosan show an intrinsic anticoagulant activity and can be combined with other polysaccharides, fucoidan and chondroitin sulfate, to produce NPs for the control of the coagulation cascade [118]. Chitosan NPs can be also loaded with factor VIII-encoding DNA and orally administered as an unconventional hemophilia A handling [119,120].
Two outstanding applications of PLGA nanoparticles have been studied for immune thrombocytopenic purpura and thalassemia, respectively. In the first case, a NP core of PLGA was covered by a platelet membranes coating, which presents all the typical platelet proteins able to partially neutralized the effects of anti-platelet antibodies and minimize the disease burden [121]. Thalassemia can be early detected during pregnancy, thus it is possible to administer intravenous or intra-amniotic PLGA NPs encapsulating peptide nucleic acid and donor DNA to correct the mutation of $\beta$-globin gene of the foetus $[122,123]$.

There are several chemotherapeutic or anti-inflammatory drugs encapsulated in lipids and this practice has been proven to be effective enhancing the local concentration in inflamed tissues, reducing the exposure of other organs and also protecting the drug from degradation.

For instance, short interfering RNAs (siRNA) [124,125] or antisense oligonucleotides against $\mathrm{Bcl}-2$ [126] can silence proliferation or antiapoptotic genes overexpressed in many tumors and, in combination with a lower dose of chemotherapeutic, can induce the remission of cancer. To prolong their circulation time, they can be encapsulated in liposomes and, to improve their target ability, functionalized with antiCD20 antibodies.

Glucocorticoids are employed in clinic for the treatment of a variety of inflammatory driven malignancies, including multiple myeloma, eventually in combination with other chemotherapeutic drugs. However, they produce severe side effects like systemic immunosuppression, osteoporosis, hypertension and others, they have also a rapid clearance and a request of frequent administrations.

The therapeutic efficacy of dexamethasone is improved by liposomal encapsulation [127]. Some chemotherapeutic drugs, such as curcumin and doxorubicin [128], tamibarotene [129], carfilzomib and doxorubicin [130], gemcitabine [131], paclitaxel, docetaxel, SN38, etoposide, hydroxytamoxifen, miltefosine, or a ferrocenyl complex and decitabine [132], methotrexate [133], arsenic troxide [134], lead to a high complete remission of blood malignancies, but they cause also cardiac and other organs dysfunctions, protein inhibition and interaction with many biological reactions, so their use is limited for human treatment because of their toxic comorbidities. To specifically deliver these drugs to cancer cells, avoiding side effects, they can be encapsulated in liposomes. A special case of chemotherapeutic into liposomes is the ex-vivo modification of T-cells to carry SN-38-loaded lipid nanocapsule to lymphoma cells, taking the advantage of the tissuehoming ability of lymphocytes [135].

Liposomes can encapsulate drugs for different medical purposes: thrombin inhibitors, able to exert an anticoagulant activity in case of arterial acute thrombosis [136], mRNA to encode erythropoietin, factor IX protein [137] and anti-factor VIII antibodies [138,139] for haemophilia treatment and Tmprss6 siRNA for thalassemia cure [140].

Solid lipid NPs (SLNPs) are nanocarriers used as an alternative to polymeric NPs since they present a lipid core, which encapsulates lipophilic drugs controlling their release by increasing their solubility, bioavailability and pharmacokinetic profile in case of naturalderived anticancer drugs, such as AP9-cd [141] and curcumin [142]. SLNPs can reduce the toxicity of many chemotherapeutic drugs: hydroxychloroquine can be encapsulated in anti-CD20 functionalized PEG-PLGA NPs [143], daunorubicin and tetrandrine in PEG-PLLPLGA NPs [144], parthenolide in PEG-PLA and silicon, bendamustine in PEG-PLGA [145], doxorubicin in PEG-PCL/Pluronic 105 micelles 
[146], paclitaxel in transferrin decorated SLNPs [147] and vincristine both in polyphenolic bioflavonoids [148] or folic acid decorated SLNPs [149].

\section{Nanoparticle-based theranostics}

Various NPs act as multifunctional nanotools and can be used both for the detection and the treatment of such haematological cancers. Referring to AuNPs, their diagnostic capability is carried out exploiting their high absorption and scattering of light, while the high surface-tovolume ratio, afford their use as nanocarriers for drugs. AuNPs, with or without further funzionalization [150], sustain cancer diagnosis and the delivery of drugs such as the Fms-like tyrosin kinase inhibitors (midostaurin, sorafenib, lestaurtinib and quizartinib) [151-153].

Transferrin (Tf)- luminescent blue copper nanoclusters are coupled with doxorubicin for theranostics applications. When NPs are internalized in TfR overexpressed cells, it is possible to simultaneously detect the blue emission of transferrin into the cytoplasm and, the gradual release of doxorubicin in the nucleus through Förster Resonance Energy Transfer (FRET) [154].

Lanthanide-doped nanoparticles can be employed as bioimaging tool for their photoluminescent properties [155] and loaded with therapeutic cargoes and targeting molecules for a therapeutic use against acute myeloid leukemia cells [156].

Also liposomes can be engineered for theranostics application: they can be loaded with superparamagnetic iron oxide NPs (SPIONs) and detected by magnetic resonance or positron emission tomography for tracking and treatment monitoring. SPIONs are covered with liposomes and then functionalized with Rituximab for increase their targeting ability and, coated with tween 80 to increase their circulation time and their penetration across the blood brain barrier (BBB) to reach also central nervous system lymphoma [157].

Core-shell chitosan-hyaluronic acid-NPs decorated with peptide pA20-36 were used to specifically target B-cell lymphoma and induce cells death in a caspase-dependent manner while fluorescent tracer and a paramagnetic agent allowed NPs internalization imaging [158].

Also Calcium phosphosilicate NPs can be engineered, once loaded with indocyanine green and functionalized with CD96 and CD117 antibodies, they can be endocytosed by leukemic cells, allowing the detection of the disease and the application of the photodynamic therapy [159].

\section{Conclusion}

To conclude here we have reviewed the broad panorama of nanoparticles, which represent one of the most useful alternative solution to manage blood diseases providing innovative non-invasive approaches for diagnosis and treatment.

Although a large number of NPs-containing drugs have already received FDA approval (Table 1) or are at present involved in studies or clinical trials (Tables 2 and 3), NPs healthcare use requires improved chemical-physical characterization, better definition of their potential toxicity concerns and more detailed regulatory guidelines.

However, there is no doubt that the rapid progress of the engineering of new materials and the implementation of new methods in the nanotechnology field will lead to the design and

Table 1. Drugs already approved by FDA for hematological disease treatment

\begin{tabular}{|c|c|c|c|c|c|}
\hline \multirow{2}{*}{ Name } & \multicolumn{2}{|l|}{ Composition } & \multirow{2}{*}{ Disease } & \multirow{2}{*}{ Year of approval } & \multirow{2}{*}{ References } \\
\hline & NPs & Active substances & & & \\
\hline $\begin{array}{l}\text { CosmoFer/ INFeD/ } \\
\text { Ferrisat }\end{array}$ & Iron dextrane colloid & & Iron deficient anemia & 1992, FDA & {$[160]$} \\
\hline Doxil/ Caelyx & Liposomes & Doxorubicin & Multiple myeloma & 1995, FDA & {$[161,162]$} \\
\hline DexFerrum/ DexIron & Iron dextrane colloid & & Iron deficient anemia & 1996, FDA & {$[163]$} \\
\hline Depocyt & Liposomes & Cytarabine & Lymphomatous meningitis & 1999, FDA & {$[164,165]$} \\
\hline FerrIecit & Iron gluconate colloid & & $\begin{array}{l}\text { Anemia treatment in patients with } \\
\text { chronic kidney disease }\end{array}$ & 1999, FDA & {$[166]$} \\
\hline Venofer & Iron sucrose colloid & & $\begin{array}{l}\text { Anemia treatment in patients with } \\
\text { chronic kidney disease }\end{array}$ & 2000, FDA & {$[167]$} \\
\hline Oncaspar & Liposomes & Asparaginase & Acute lymphoblastic leukemia & 2006, FDA & {$[168]$} \\
\hline Feraheme & $\begin{array}{l}\text { Iron polyglucose sorbitol } \\
\text { carboxymethylether colloid }\end{array}$ & & $\begin{array}{l}\text { Anemia treatment in patients with } \\
\text { chronic kidney disease }\end{array}$ & 2009, FDA & [169] \\
\hline Monofer & Iron isomaltoside colloid & & $\begin{array}{l}\text { Iron deficient anemia when oral } \\
\text { method do not work or iron delivery } \\
\text { is required immediately }\end{array}$ & 2009, some of Europe & {$[170]$} \\
\hline Marqibo & Liposomes & Vincristine & Acute lymphoblastic leukemia & 2012, FDA & {$[171,172]$} \\
\hline Diafer & Iron isomaltoside colloid & & Iron deficient anemia & 2012, some of Europe & {$[173]$} \\
\hline Injectafer/ Ferinject & Iron carboxymaltose colloid & & Iron deficient anemia & 2013, FDA & {$[174]$} \\
\hline Vyxeos & Liposomes & Daunorubicin and cytarabine & Acute myeloid leukemia & 2017, FDA & {$[175-177]$} \\
\hline
\end{tabular}

Table 2. Drugs already approved by FDA for other application that are now studied or under clinical trials to for hematological malignancies applications

\begin{tabular}{|l|l|l|l|l|}
\hline \multirow{2}{*}{ Name } & Composition & Disease & Year-Target FDA approval \\
\cline { 2 - 3 } & NPs & Active substances & $\begin{array}{l}\text { Acute Myeloid/ Lymphoblastic } \\
\text { Leukemia }\end{array}$ & 1996-HIV Kaposi's sarcoma \\
\hline Myocet & Daunorubicin & Lymphoma & 2000-metastatic breast cancer \\
\hline Abraxane & Liposomes & Doxorubicin & Lymphoma & 2005-breast, lung and pancreatic cancer \\
\hline
\end{tabular}


Table 3. Drugs currently under clinical trials

\begin{tabular}{|c|c|c|c|c|c|}
\hline \multirow{2}{*}{ Name } & \multicolumn{2}{|l|}{ Composition } & \multirow{2}{*}{ Disease } & \multirow{2}{*}{ Clinical trial.gov identifier (Phase) } & \multirow{2}{*}{ References } \\
\hline & NPs & Active substances & & & \\
\hline ABI-011 & Albumin & Thiocolchicine analog & Lymphoma & $\begin{array}{l}\text { NCT02582827 (I) } \\
\text { NCT01163071 (I) }\end{array}$ & [184] \\
\hline AZD2811 & Polymers & Aurora B kinase inhibitor & $\begin{array}{l}\text { Acute myeloid } \\
\text { leukemia }\end{array}$ & NCT03217838 (I, II) & {$[109,185]$} \\
\hline BP1001 & Liposomes & $\begin{array}{l}\text { Growth factor receptor } \\
\text { bound protein-2 antisense } \\
\text { oligonucleotide }\end{array}$ & Leukemia & $\begin{array}{l}\text { NCT02923986 (I, II) } \\
\text { NCT02781883 (II) } \\
\text { NCT01159028 (I) }\end{array}$ & [186-188] \\
\hline DCR-MYC & Liposomes & $\begin{array}{l}\text { DsiRNA for MYC oncogene } \\
\text { silencing }\end{array}$ & $\begin{array}{l}\text { Multiple myeloma and } \\
\text { lymphoma }\end{array}$ & NCT02110563 (I) & {$[189,190]$} \\
\hline JVRS-100 & Liposomes & Plasmid DNA complex & Leukemia & NCT00860522 (I) & [191] \\
\hline $\begin{array}{l}\text { Mitoxantrone } \\
\text { hydrochloride liposome }\end{array}$ & Liposomes & Mitoxantrone & $\begin{array}{l}\text { Leukemias and } \\
\text { lymphoma }\end{array}$ & $\begin{array}{l}\text { NCT02043756 (I) } \\
\text { NCT02131688 (I) } \\
\text { NCT02856685 (I, II) } \\
\text { NCT03776279 (II) } \\
\text { NCT02595242 (I) } \\
\text { NCT02597387 (II) } \\
\text { NCT02597153 (II) } \\
\text { NCT02879643 (I) } \\
\text { NCT02518750 (II) } \\
\text { NCT02733380 (II) } \\
\text { NCT02724163 (III) } \\
\text { NCT03591510 (II) }\end{array}$ & [192-194] \\
\hline $\begin{array}{l}\text { NC-4016 DACH-Platin } \\
\text { micelle }\end{array}$ & $\begin{array}{l}\text { Polyamino acid and } \\
\text { PEG }\end{array}$ & Oxaliplatin & Lymphoma & NCT03168035 (I) & [195] \\
\hline PNT2258 & Liposomes & Single-stranded DNAi & Lymphoma & $\begin{array}{l}\text { NCT02378038 (II) } \\
\text { NCT02226965 (II) } \\
\text { NCT01733238 (II) } \\
\text { NCT01191775 (I) }\end{array}$ & [196-198] \\
\hline
\end{tabular}

standardization of alternatives therapies specific to each patient and disease. Nanomedicine, using original and multi-faceted instruments as the NPs are, can offer the precise targeting and therapeutics tools that researchers and physicians need, to make the diagnosis and treatment techniques that they already have at their disposal even more effective and competitive.

\section{Acknowledgement}

This work has received funding from the European Research Council (ERC) under the European Union's Horizon 2020 research and innovation programme (grant agreement No 678151 - Project Acronym “TROJANANOHORSE” - ERC starting Grant).

\section{References}

1. Jeevanandam J, Barhoum A, Chan YS, Dufresne A (2018) Review on nanoparticles and nanostructured materials: history, sources, toxicity and regulations. Beilstein J Nanotechnol 9: 1050-1074. [Crossref]

2. Singh R, Lillard JW (2009) Nanoparticle-based targeted drug delivery. Experimental and Molecular Pathology 86: 215-223

3. Jahangirian H, Kalantari K, Izadiyan Z, Rafiee-Moghaddam R, Shameli K, et al. (2019) A review of small molecules and drug delivery applications using gold and iron nanoparticles. Int J Nanomedicine 14: 1633-1657.

4. Kerry RG, Malik S, Redda YT, Sahoo S, Patra JK, et al. (2019) Nano-based approach to combat emerging viral (NIPAH virus) infection. Nanomedicine.

5. Mi Y, Hagan CT, Vincent BG, Wang AZ (2019) Emerging Nano-/Microapproaches for Cancer Immunotherapy. Adv Sci (Weinh) 6: 1801847. [Crossref]

6. Teleanu DM, Negut I, Grumezescu V, Grumezescu AM, Teleanu RI (2019) Nanomaterials for Drug Delivery to the Central Nervous System. Nanomaterials (Basel) p. 9

7. Yang H, Marion TN, Liu Y, Zhang L, Cao X, et al. (2019) Nanomaterial Exposure Induced Neutrophil Extracellular Traps: A New Target in Inflammation and Innate Immunity. J Immunol Res 2019: 3560180

8. Brazzale C, Canaparo R, Racca L, Foglietta F, Durando G, et al. (2016) Enhanced selective sonosensitizing efficacy of ultrasound-based anticancer treatment by targeted gold nanoparticles. Nanomedicine (Lond) 11: 3053-3070. [Crossref]
9. Limongi T, Canta M, Racca L, Ancona A, Tritta S, Vighetto V, et al. Improving dispersa of therapeutic nanoparticles in the human body. Nanomedicine (Lond) 14: 797-801.

10. Gupta TK, Budarapu PR, Chappidi SR, Sastry SY, Paggi M, et al. (2018) Advances in carbon based nanomaterials for bio-medical applications. Curr Med Chem. [Crossref]

11. Passacantando M (2009) Simultaneous growth of MWCNTs at different temperatures in a variable gradient furnace.

12. Castro E, Hernandez Garcia A, Zavala G, Echegoyen L (2017) Fullerenes in Biology and Medicine. J Mater Chem B 5: 6523-6535. [Crossref]

13. Augustine S, Singh J, Srivastava M, Sharma M, Das A, et al. (2017) Recent advances in carbon based nanosystems for cancer theranostics. Biomaterials Science 5: 901-952.

14. Maiti D, Tong X, Mou X, Yang K (2019) Carbon-Based Nanomaterials for Biomedical Applications: A Recent Study. Frontiers in Pharmacology p. 9.

15. Limongi T, Tirinato L, Pagliari F, Giugni A, Allione M, et al. (2017) Fabrication and Applications of Micro/Nanostructured Devices for Tissue Engineering. Nanomicro Lett 9: 1.

16. El-Say KM, El-Sawy HS (2017) Polymeric nanoparticles: Promising platform for drug delivery. Int J Pharm 528: 675-691.

17. Crucho CIC, Barros MT (2017) Polymeric nanoparticles: A study on the preparation variables and characterization methods. Mater Sci Eng C Mater Biol Appl 80: 771-784.

18. Alavi M, Karimi N, Safaei M (2017) Application of Various Types of Liposomes in Drug Delivery Systems. Adv Pharm Bull 7: 3-9. [Crossref]

19. Mozafari MR (2005) Liposomes: an overview of manufacturing techniques. Cell Mol Biol Lett 10: 711-719. [Crossref]

20. Mauricio MD, Guerra-Ojeda S, Marchio P, Valles SL, Aldasoro M, et al. (2018) Nanoparticles in Medicine: A Focus on Vascular Oxidative Stress. Oxidative Medicine and Cellular Longevity 2018: 20.

21. Dumontel B, Canta M, Engelke H, Chiodoni A, Racca L, et al. (2017) Enhanced biostability and cellular uptake of zinc oxide nanocrystals shielded with a phospholipid bilayer. J Mater Chem B 5: 8799-8813. [Crossref]

22. Cauda V, Engelke H, Sauer A, Arcizet D, Brauchle C, et al. (2010) Colchicine-loaded lipid bilayer-coated $50 \mathrm{~nm}$ mesoporous nanoparticles efficiently induce microtubule depolymerization upon cell uptake. Nano Lett 10: 2484-2492.

23. Mathieu M, Martin-Jaular L, Lavieu G, Thery C (2019) Specificities of secretion and uptake of exosomes and other extracellular vesicles for cell-to-cell communication. Nat Cell Biol 21: 9-17. 
24. Fernandes M, Lopes I, Teixeira J, Botelho C, Gomes AC (2019) Exosome-Like Nanoparticles: A New Type Of Nanocarrier. Curr Med Chem. [Crossref]

25. Illes B, Hirschle P, Barnert S, Cauda V, Wuttke S, et al. (2017) Exosome-Coated MetalOrganic Framework Nanoparticles: An Efficient Drug Delivery Platform. Chemistry of Materials 29: 8042-8046.

26. Fais S, O’Driscoll L, Borras FE, Buzas E, Camussi G, et al. (2016) Evidence-Based Clinical Use of Nanoscale Extracellular Vesicles in Nanomedicine. ACS Nano 10: 3886-3899.

27. Vallabani NVS, Singh S, Karakoti A (2018) Magnetic Nanoparticles: Current Trends and Future Aspects in Diagnostics and Nanomedicine. Curr Drug Metab.

28. Marino A, Battaglini M, De Pasquale D, Degl'Innocenti A, Ciofani G (2018) Ultrasound-Activated Piezoelectric Nanoparticles Inhibit Proliferation of Breast Cancer Cells. Scientific Reports 8: 6257.

29. Perrone Donnorso M, Miele E, De Angelis F, La Rocca R, Limongi T, et al. (2012) Nanoporous silicon nanoparticles for drug delivery applications. Microelectronic Engineering 98: 626-629.

30. Brazzale C, Canaparo R, Racca L, Foglietta F, Durando G, et al. (2016) Enhanced selective sonosensitizing efficacy of ultrasound-based anticancer treatment by targeted gold nanoparticles. Nanomedicine 11: 3053-3070.

31. Garino N, Limongi T, Dumontel B, Canta M, Racca L, et al. (2019) A MicrowaveAssisted Synthesis of Zinc Oxide Nanocrystals Finely Tuned for Biological Applications. Nanomaterials (Basel) p. 9.

32. Yeh YT, Tang Y, Sebastian A, Dasgupta A, Perea-Lopez N, et al. (2016) Tunable and label-free virus enrichment for ultrasensitive virus detection using carbon nanotube arrays. Science advances 2: e1601026-e1601026.

33. BSN, Tvn P, Suganya KSU, Govindaraju K, Kumar G (2016) Facile green synthesis of carbon nanoparticles using medicinally potent Pongamia pinnata shoots. Journal of Environment and Biotechnology Research 3: 12-16.

34. Banerjee D, Harfouche R, Sengupta S (2011) Nanotechnology-mediated targeting of tumor angiogenesis. Vascular cell 3: 3-3.

35. Hua S, Vaughan B (2019) In vitro comparison of liposomal drug delivery systems targeting the oxytocin receptor: a potential novel treatment for obstetric complications. Int J Nanomedicine 14: 2191-2206.

36. Aminabad NS, Farshbaf M, Akbarzadeh A (2018) Recent Advances of Gold Nanoparticles in Biomedical Applications: State of the Art. Cell Biochem Biophys 77: 123-137.

37. Shariatifar H, Hakhamaneshi MS, Abolhasani M, Ahmadi FH, Roshani D, et al. (2019) Immunofluorescent labeling of CD20 tumor marker with quantum dots for rapid and quantitative detection of diffuse large B-cell non-Hodgkin's lymphoma. J Cell Biochem 120: 4564-4572.

38. Yu Y, Duan S, He J, Liang W, Su J, et al. (2016) Highly sensitive detection of leukemia cells based on aptamer and quantum dots. Oncol Rep 36: 886-892.

39. Sahoo SL, Liu CH, Wu WC (2017) Lymphoma cell isolation using multifunctional magnetic nanoparticles: antibody conjugation and characterization. RSC Advances 7 : 22468-22478.

40. Zhou Y, Xie Q (2016) Hyaluronic acid-coated magnetic nanoparticles-based selective collection and detection of leukemia cells with quartz crystal microbalance. Sensors and Actuators B: Chemical 223: 9-14

41. Vinhas R, Correia C, Ribeiro P, Lourenço A, Botelho de Sousa A, et al. (2016) Colorimetric assessment of BCR-ABL1 transcripts in clinical samples via gold nanoprobes. Anal Bioanal Chem 408: 5277-5284. [Crossref]

42. Cordeiro M, Giestas L, Lima JC, Baptista PM (2016) BioCode gold-nanobeacon for the detection of fusion transcripts causing chronic myeloid leukemia. J Nanobiotechnology 14: 38 .

43. Mazloum-Ardakani M, Barazesh B, Khoshroo A, Moshtaghiun M, Sheikhha MH (2018) A new composite consisting of electrosynthesized conducting polymers, graphene sheets and biosynthesized gold nanoparticles for biosensing acute lymphoblastic leukemia. Bioelectrochemistry 121: 38-45.

44. Shiang YC, Huang CC, Wang TH, Chien CW, Chang HT (2010) Aptamer-Conjugated Nanoparticles Efficiently Control the Activity of Thrombin. Advanced Functional Materials 20: 3175-3182.

45. Liao YJ, Shiang YC, Huang CC, Chang HT (2012) Molecularly imprinted aptamers of gold nanoparticles for the enzymatic inhibition and detection of thrombin. Langmuir 28: 8944-8951.
46. Chandrawati R, Stevens MM (2014) Controlled assembly of peptide-functionalized gold nanoparticles for label-free detection of blood coagulation Factor XIII activity. Chemical Communications 50: 5431-5434.

47. Zhang M, Liu H, Chen L, Yan M, Ge L, et al. (2013) A disposable electrochemiluminescence device for ultrasensitive monitoring of K562 leukemia cells based on aptamers and $\mathrm{ZnO} @$ carbon quantum dots. Biosensors and Bioelectronics 49: 79-85.

48. Sharma A, Pandey CM, Sumana G, Soni U, Sapra S, et al. (2012) Chitosan encapsulated quantum dots platform for leukemia detection. Biosens Bioelectron 38: 107-113.

49. Bahreyni A, Yazdian-Robati R, Ramezani M, Rasouli M, Alinezhad Nameghi M, et al. (2017) Identification and imaging of leukemia cells using dual-aptamer-functionalized graphene oxide complex. J Biomater Appl 32: 74-81.

50. Khoshfetrat SM, Mehrgardi MA (2017) Amplified detection of leukemia cancer cells using an aptamer-conjugated gold-coated magnetic nanoparticles on a nitrogen-doped graphene modified electrode. Bioelectrochemistry 114: 24-32.

51. Tan J, Yang N, Hu Z, Su J, Zhong J, et al. (2016) Aptamer-Functionalized Fluorescen Silica Nanoparticles for Highly Sensitive Detection of Leukemia Cells. Nanoscale Res Lett 11: 298 .

52. Shan W, Pan Y, Fang H, Guo M, Nie Z, et al. (2014) An aptamer-based quartz crystal microbalance biosensor for sensitive and selective detection of leukemia cells using silver-enhanced gold nanoparticle label. Talanta 126: 130-135.

53. Khetani A, Momenpour A, Alarcon EI, Anis H (2015) Hollow core photonic crysta fiber for monitoring leukemia cells using surface enhanced Raman scattering (SERS). Biomedical optics express 6: 4599-4609.

54. MacLaughlin CM, Mullaithilaga N, Yang G, Ip SY, Wang C, et al. (2013) Surfaceenhanced Raman scattering dye-labeled Au nanoparticles for triplexed detection of leukemia and lymphoma cells and SERS flow cytometry. Langmuir 29: 1908-1919.

55. Long S, Qin Q, Wang Y, Yang Y, Wang Y, et al. (2019) Nanoporous silica coupled MALDI-TOF MS detection of Bence-Jones proteins in human urine for diagnosis of multiple myeloma. Talanta 200: 288-292.

56. Rutberg FG, Dubina MV, Kolikov VA, Moiseenko FV, Ignat'eva EV, et al. (2008) Effect of silver oxide nanoparticles on tumor growth in vivo. Dokl Biochem Biophys 421: 191-193.

57. Sriram MI, Kanth SBM, Kalishwaralal K, Gurunathan S (2010) Antitumor activity of silver nanoparticles in Dalton's lymphoma ascites tumor model. International journal of nanomedicine 5: 753-762.

58. Avalos A, Haza AI, Mateo D, Morales P (2014) Cytotoxicity and ROS production of manufactured silver nanoparticles of different sizes in hepatoma and leukemia cells. $J$ Appl Toxicol 34:413-423.

59. Antony JJ, Sithika MA, Joseph TA, Suriyakalaa U, Sankarganesh A, et al. (2013) In vivo antitumor activity of biosynthesized silver nanoparticles using Ficus religiosa as a nanofactory in DAL induced mice model. Colloids Surf B Biointerfaces 108: 185-190.

60. Kumar S, Tomar MS, Acharya A (2015) Carboxylic group-induced synthesis and characterization of selenium nanoparticles and its anti-tumor potential on Dalton's lymphoma cells. Colloids Surf B Biointerfaces 126: 546-552.

61. Shafagh M, Rahmani F, Delirezh N (2015) CuO nanoparticles induce cytotoxicity and apoptosis in human K562 cancer cell line via mitochondrial pathway, through reactive oxygen species and P53. Iran J Basic Med Sci 18: 993-1000.

62. Chattopadhyay S, Dash SK, Tripathy S, Das B, Kar Mahapatra S, et al. (2015) Cobalt oxide nanoparticles induced oxidative stress linked to activation of TNF-alpha/ caspase-8/p38-MAPK signaling in human leukemia cells. J Appl Toxicol 35: 603-613.

63. Shahriari S, Bakhshi M, Shahverdi AR, Berahmeh A, Safavifar F, et al. (2017) Targeted Intracellular Heat Transfer in Cancer Therapy: Assessment of Asparagine-laminated Gold Nanoparticles in Cell Model of T cell Leukemia. Iranian journal of public health 46: 357-367.

64. Lin YR, Chan CH, Lee HT, Cheng SJ, Yang JW, et al. (2019) Remote Magnetic Control of Autophagy in Mouse B-Lymphoma Cells with Iron Oxide Nanoparticles. Nanomaterials (Basel) p. 9.

65. Zhang W, Qiao L, Wang X, Senthilkumar R, Wang F, et al. (2015) Inducing cell cycle arrest and apoptosis by dimercaptosuccinic acid modified Fe3O4 magnetic nanoparticles combined with nontoxic concentration of bortezomib and gambogic acid in RPMI-8226 cells. Int J Nanomedicine 10: 3275-3289.

66. Ancona A, Dumontel B, Garino N, Demarco B, Chatzitheodoridou D, et al (2018) Lipid-Coated Zinc Oxide Nanoparticles as Innovative ROS-Generators for Photodynamic Therapy in Cancer Cells. Nanomaterials (Basel) p. 8. 
67. Guo D, Wu C, Jiang H, Li Q, Wang X, et al. (2008) Synergistic cytotoxic effect of different sized $\mathrm{ZnO}$ nanoparticles and daunorubicin against leukemia cancer cells under UV irradiation. J Photochem Photobiol B 93: 119-126.

68. Luengas SP, Marin G, Rodriguez Nieto F, Dreon M, Roque G, et al. (2015) B-chronic lymphocytic leukemia autophagyc cell death by the use of manganese doped zinc oxide nanoparticles and photo-dynamic therapy.

69. Barnaby SN, Lee A, Mirkin CA (2014) Probing the inherent stability of siRNA immobilized on nanoparticle constructs. Proc Natl Acad Sci U S A 111: 9739-9744.

70. Vinhas R, Fernandes AR, Baptista PV (2017) Gold Nanoparticles for BCR-ABL1 Gene Silencing: Improving Tyrosine Kinase Inhibitor Efficacy in Chronic Myeloid Leukemia. Mol Ther Nucleic Acids 7: 408-416.

71. Radovic-Moreno AF, Chernyak N, Mader CC, Nallagatla S, Kang RS, et al. (2015) Immunomodulatory spherical nucleic acids. Proceedings of the National Academy of Sciences 112: 3892.

72. Podsiadlo P, Sinani VA, Bahng JH, Kam NW, Lee J, et al. (2008) Gold nanoparticles enhance the anti-leukemia action of a 6-mercaptopurine chemotherapeutic agent. Langmuir 24: 568-574.

73. Song S, Hao Y, Yang X, Patra P, Chen J (2016) Using Gold Nanoparticles as Delivery Vehicles for Targeted Delivery of Chemotherapy Drug Fludarabine Phosphate to Treat Hematological Cancers. J Nanosci Nanotechnol 16: 2582-2586.

74. Deng R, Shen N, Yang Y, Yu H, Xu S, et al. (2018) Targeting epigenetic pathway with gold nanoparticles for acute myeloid leukemia therapy. Biomaterials 167: 80-90.

75. Adena SKR, Upadhyay M, Vardhan H, Mishra B (2019) Gold nanoparticles for sustained antileukemia drug release: development, optimization and evaluation by quality-by-design approach. Nanomedicine (Lond) 14: 851-870.

76. Chen B, Cheng J, Shen M, Gao F, Xu W, et al. (2009) Magnetic nanoparticle of Fe3O4 and 5-bromotetrandrin interact synergistically to induce apoptosis by daunorubicin in leukemia cells. Int J Nanomedicine 4: 65-71.

77. Shahabadi N, Falsafi M, Mansouri K (2016) Improving antiproliferative effect of the anticancer drug cytarabine on human promyelocytic leukemia cells by coating on Fe3O4@SiO2 nanoparticles. Colloids Surf B Biointerfaces 141: 213-222.

78. Chen D, Chen B, Yao F (2018) Doxorubicin-Loaded PEG-CdTe Quantum Dots as a Smart Drug Delivery System for Extramedullary Multiple Myeloma Treatment. Nanoscale Res Lett 13: 373 .

79. Yang C, Xiong F, Wang J, Dou J, Chen J, et al. (2014) Anti-ABCG2 monoclonal antibody in combination with paclitaxel nanoparticles against cancer stem-like cell activity in multiple myeloma. Nanomedicine (Lond) 9: 45-60.

80. Shafie EH, Keshavarz SA, Kefayati ME, Taheri F, Sarbakhsh P, et al. (2016) The Effects of Nanoparticles Containing Iron on Blood and Inflammatory Markers in Comparison to Ferrous Sulfate in Anemic Rats. Int J Prev Med 7: 117.

81. Zariwala MG, Elsaid N, Jackson TL, Corral Lopez F, Farnaud S, et al. (2013) A novel approach to oral iron delivery using ferrous sulphate loaded solid lipid nanoparticles. Int J Pharm 456: 400-407.

82. Hosny KM, Banjar ZM, Hariri AH, Hassan AH (2015) Solid lipid nanoparticles loaded with iron to overcome barriers for treatment of iron deficiency anemia. Drug Des Devel Ther 9: 313-320.

83. Hashem F, Nasr M, Ahmed Y (2018) Preparation And Evaluation Of Iron Oxide Nanoparticles For Treatment Of Iron Deficiency Anemia. IJPPS 10: 1

84. Garces V, Rodriguez-Nogales A, Gonzalez A, Galvez N, Rodriguez-Cabezas ME, et al. (2018) Bacteria-Carried Iron Oxide Nanoparticles for Treatment of Anemia. Bioconjug Chem 29: 1785-1791.

85. Shafir G, Galperin A, Margel S (2009) Synthesis and characterization of recombinant factor VIIa-conjugated magnetic iron oxide nanoparticles for hemophilia treatment. $J$ Biomed Mater Res A 91: 1056-1064

86. Shabanova EM, Drozdov AS, Fakhardo AF, Dudanov IP (2018) Thrombin@Fe3O4 nanoparticles for use as a hemostatic agent in internal bleeding. Sci Rep 8: 233. [Crossref]

87. Ehmann HM, Breitwieser D, Winter S, Gspan C, Koraimann G, et al. (2015) Gold nanoparticles in the engineering of antibacterial and anticoagulant surfaces. Carbohydr Polym 117: 34-42.

88. Huang SS, Wei SC, Chang HT, Lin HJ, Huang CC (2016) Gold nanoparticles modified with self-assembled hybrid monolayer of triblock aptamers as a photoreversible anticoagulant. J Control Release 221: 9-17.
89. Yang JY, Bae J, Jung A, Park S, Chung S, et al. (2017) Surface functionalizationspecific binding of coagulation factors by zinc oxide nanoparticles delays coagulation time and reduces thrombin generation potential in vitro. PLoS One 12: e 0181634.

90. Lateef A, Ojo S, Oladejo S (2016) Anti-candida, anti-coagulant and thrombolytic activities of biosynthesized silver nanoparticles using cell-free extract of Bacillus safensis LAU 13.

91. Lateef A, Ojo S, Elegbede J, Azeez M, Yekeen T, et al. (2017) Evaluation of Some Biosynthesized Silver Nanoparticles for Biomedical Applications: Hydrogen Peroxide Scavenging, Anticoagulant and Thrombolytic Activities. Journal of Cluster Science 28: 1379-1392.

92. Heise K, Hobisch M, Sacarescu L, Maver U, Hobisch J, et al. (2018) Low-molecularweight sulfonated chitosan as template for anticoagulant nanoparticles. Int $J$ Nanomedicine 13: 4881-4894.

93. Mandal T, Beck M, Kirsten N, Linden M, Buske C (2018) Targeting murine leukemic stem cells by antibody functionalized mesoporous silica nanoparticles. Sci Rep 8: 989.

94. de la Torre C, Casanova I, Acosta G, Coll C, Moreno MJ, et al. (2015) Gated Mesoporous Silica Nanoparticles Using a Double-Role Circular Peptide for the Controlled and Target-Preferential Release of Doxorubicin in CXCR4-Expresing Lymphoma Cells Advanced Functional Materials 25: 687-695.

95. Srivastava P, Hira SK, Sharma A, Kashif M, Srivastava P, et al. (2018) Telomerase Responsive Delivery of Doxorubicin from Mesoporous Silica Nanoparticles in Multiple Malignancies: Therapeutic Efficacies against Experimental Aggressive Murine Lymphoma. Bioconjug Chem 29: 2107-2119.

96. Srivastava P, Hira SK, Gupta U, Singh VK, Singh R, et al. (2018) Pepsin Assisted Doxorubicin Delivery from Mesoporous Silica Nanoparticles Downsizes Solid Tumor Volume and Enhances Therapeutic Efficacy in Experimental Murine Lymphoma. ACS Applied Bio Materials 1: 2133-2140.

97. Srivastava P, Hira SK, Srivastava DN, Singh VK, Gupta U, et al. (2018) ATP-Decorated Mesoporous Silica for Biomineralization of Calcium Carbonate and P2 Purinergic Receptor-Mediated Antitumor Activity against Aggressive Lymphoma. ACS Appl Mater Interfaces 10: 6917-6929.

98. Durfee PN, Lin YS, Dunphy DR, Muniz AJ, Butler KS, et al. (2016) Mesoporous Silica Nanoparticle-Supported Lipid Bilayers (Protocells) for Active Targeting and Delivery to Individual Leukemia Cells. ACS Nano 10: 8325-8345.

99. Mackowiak SA, Schmidt A, Weiss V, Argyo C, von Schirnding C, et al. (2013) Targeted drug delivery in cancer cells with red-light photoactivated mesoporous silica nanoparticles. Nano Lett 13: 2576-2583.

100. Devineau S, Kiger L, Galacteros F, Baudin-Creuza V, Marden M, et al. (2018) Manipulating hemoglobin oxygenation using silica nanoparticles: a novel prospect for artificial oxygen carriers. Blood Adv 2: 90-94.

101. Liu M, Gan L, Chen L, Zhu D, Xu Z, et al. (2012) A novel liposome-encapsulated hemoglobin/silica nanoparticle as an oxygen carrier. Int J Pharm 427: 354-357.

102. Bhat R, Ribes À, Mas N, Aznar E, Sancenón F, et al. (2016) Thrombin-Responsive Gated Silica Mesoporous Nanoparticles As Coagulation Regulators. Langmuir 32: 1195-1200.

103. Riccardi C, Russo Krauss I, Musumeci D, Morvan F, Meyer A, et al. (2017) Fluorescent Thrombin Binding Aptamer-Tagged Nanoparticles for an Efficient and Reversible Control of Thrombin Activity. ACS Appl Mater Interfaces 9: $35574-$ 35587.

104. Argyo C, Cauda V, Engelke H, Radler J, Bein G, et al. (2012) Heparin-coated colloidal mesoporous silica nanoparticles efficiently bind to antithrombin as an anticoagulant drug-delivery system. Chem Eur J 18: 428-432.

105. Punfa W, Yodkeeree S, Pitchakarn P, Ampasavate C, Limtrakul P (2012) Enhancement of cellular uptake and cytotoxicity of curcumin-loaded PLGA nanoparticles by conjugation with anti-P-glycoprotein in drug resistance cancer cells. Acta Pharmacol $\operatorname{Sin} 33: 823-831$

106. Leung MHM, Shen AQ (2018) Microfluidic Assisted Nanoprecipitation of PLGA Nanoparticles for Curcumin Delivery to Leukemia Jurkat Cells. Langmuir 34: 39613970.

107. Babar IA, Cheng CJ, Booth CJ, Liang X, Weidhaas JB, et al. (2012) Nanoparticlebased therapy in an in vivo microRNA-155 (miR-155)-dependent mouse model of lymphoma. Proc Natl Acad Sci U S A 109: E1695-1704.

108. Ashton S, Song YH, Nolan J, Cadogan E, Murray J, et al. (2016) Aurora kinase inhibitor nanoparticles target tumors with favorable therapeutic index in vivo. Sci Transl Med 8: 325ra317. 
109. Floc'h N, Ashton S, Taylor P, Trueman D, Harris E, et al. (2017) Optimizing Therapeutic Effect of Aurora B Inhibition in Acute Myeloid Leukemia with AZD2811 Nanoparticles. Mol Cancer Ther 16: 1031-1040.

110. Mezzaroba N, Zorzet S, Secco E, Biffi S, Tripodo C, et al. (2018) New potential therapeutic approach for the treatment of B-Cell malignancies using chlorambucil/ hydroxychloroquine-loaded anti-CD20 nanoparticles. PLoS One 8: e74216.

111. Capolla S, Garrovo C, Zorzet S, Lorenzon A, Rampazzo E, et al. (2015) Targeted tumor imaging of anti-CD20-polymeric nanoparticles developed for the diagnosis of B-cell malignancies. Int J Nanomedicine 10: 4099-4109.

112. Capolla S, Mezzaroba N, Zorzet S, Tripodo C, Mendoza-Maldonado R, et al. (2016) A new approach for the treatment of CLL using chlorambucil/hydroxychloroquineloaded anti-CD20 nanoparticles. Nano Research 9: 537-548.

113. Krishnan V, Xu X, Kelly D, Snook A, Waldman SA, et al. (2015) CD19-Targeted Nanodelivery of Doxorubicin Enhances Therapeutic Efficacy in B-Cell Acute Lymphoblastic Leukemia. Mol Pharm 12: 2101-2111.

114. Liang B, Li N, Zhang S, Qi A, Feng J, et al. (2019) Idarubicin-loaded methoxy poly(ethylene glycol)-b-poly(l-lactide-co-glycolide) nanoparticles for enhancing cellular uptake and promoting antileukemia activity. Int J Nanomedicine 14: 543-556.

115. Zilkowski I, Ziouti F, Schulze A, Hauck S, Schmidt S, et al. (2019) Nanogels Enable Efficient miRNA Delivery and Target Gene Downregulation in TransfectionResistant Multiple Myeloma Cells. Biomacromolecules 20: 916-926.

116. Pourtalebi Jahromi L, Mohammadi-Samani S, Heidari R, Azadi A (2018) in vitroand in vivo Evaluation of Methotrexate-Loaded Hydrogel Nanoparticles Intended to Treat Primary CNS Lymphoma via Intranasal Administration. J Pharm Pharm Sci 21: 305-317.

117. Jiao Y, Ubrich N, Marchand-Arvier M, Vigneron C, et al. (2002) In vitro and in vivo evaluation of oral heparin-loaded polymeric nanoparticles in rabbits. Circulation 105: 230-235.

118. da Silva LC, Garcia T, Mori M, Sandri G, Bonferoni MC, et al. (2012) Preparation and characterization of polysaccharide-based nanoparticles with anticoagulant activity. Int J Nanomedicine 7: 2975-2986.

119. Bowman K1, Sarkar R, Raut S, Leong KW (2008) Gene transfer to hemophilia A mice via oral delivery of FVIII-chitosan nanoparticles. J Control Release 132: 252259. [Crossref]

120. Dhadwar SS, Kiernan J, Wen J, Hortelano G (2010) Repeated oral administration of chitosan/DNA nanoparticles delivers functional FVIII with the absence of antibodies in hemophilia A mice. J Thromb Haemost 8: 2743-2750.

121. Wei X, Gao J, Fang RH, Luk BT, Kroll AV, et al. (2016) Nanoparticles camouflaged in platelet membrane coating as an antibody decoy for the treatment of immune thrombocytopenia. Biomaterials 111: 116-123.

122. Ricciardi AS, Bahal R, Farrelly JS, Quijano E, Bianchi AH, et al. (2018) In utero nanoparticle delivery for site-specific genome editing. Nat Commun 9: 2481.

123. Bahal R, Ali McNeer N, Quijano E, Liu Y (2016) In vivo correction of anaemia in $\hat{\mathrm{I}}^{2}$-thalassemic mice by $\hat{\mathrm{I}}^{3} \mathrm{PNA}$-mediated gene editing with nanoparticle delivery. Nat Commun 7: 13304. [Crossref]

124. Knapp CM, He J, Lister J, Whitehead KA (2016) Lipidoid nanoparticle mediated silencing of Mcl-1 induces apoptosis in mantle cell lymphoma. Exp Biol Med (Maywood) 241: 1007-1013.

125. Knapp CM, He J, Lister J, Whitehead KA (2018) Lipid nanoparticle siRNA cocktails for the treatment of mantle cell lymphoma. Bioengineering \& translational medicine 3: 138-147.

126. Yu B, Mao Y, Bai LY, Herman SE, Wang X, et al. (2013) Targeted nanoparticle delivery overcomes off-target immunostimulatory effects of oligonucleotides and improves therapeutic efficacy in chronic lymphocytic leukemia. Blood 121: 136-147.

127. Deshantri AK, Fens MH, Ruiter RWJ, Metselaar JM, Storm G, et al. (2019) Liposomal dexamethasone inhibits tumor growth in an advanced human-mouse hybrid model of multiple myeloma. J Control Release 296: 232-240.

128. Misra R, Sahoo SK (2011) Coformulation of doxorubicin and curcumin in poly(D,Llactide-co-glycolide) nanoparticles suppresses the development of multidrug resistance in K562 cells. Mol Pharm 8: 852-866.

129. Liu X, Zhang Z, Jiang Y, Hu Y, Wang Z, et al. (2015) Novel PEG-grafted nanostructured lipid carrier for systematic delivery of a poorly soluble anti-leukemia agent Tamibarotene: characterization and evaluation. Drug Deliv 22: 223-229.
130. Ashley JD, Quinlan CJ, Schroeder VA, Suckow MA, Pizzuti VJ, et al. (2016) Dual Carfilzomib and Doxorubicin-Loaded Liposomal Nanoparticles for Synergistic Efficacy in Multiple Myeloma. Mol Cancer Ther 15: 1452-1459.

131. Sasso MS, Lollo G, Pitorre M, Solito S, Pinton L, et al. (2016) Low dose gemcitabineloaded lipid nanocapsules target monocytic myeloid-derived suppressor cells and potentiate cancer immunotherapy. Biomaterials 96: 47-62.

132. Briot T, Roger E, Lautram N, Verger A, Clavreul A, et al. (2017) Development and in vitro evaluations of new decitabine nanocarriers for the treatment of acute myeloid leukemia. Int J Nanomedicine 12: 8427-8442.

133. Alekseeva AA, Moiseeva EV, Onishchenko NR, Boldyrev IA, Singin AS, et al. (2017) Liposomal formulation of a methotrexate lipophilic prodrug: assessment in tumor cells and mouse T-cell leukemic lymphoma. Int J Nanomedicine 12: 3735 3749.

134. da Rosa FC, Buque Pardinho R, Schultz Moreira ME, de Souza LGT, de Moraes Flores EM, et al. (2019) In vitro stability of arsenic trioxide-liposome encapsulates for acute promyelocytic leukemia treatment. Leuk Res 76: 11-14.

135. Huang B, Abraham WD, Zheng Y, Bustamante Lopez SC, Luo SS, Irvine DJ. Active targeting of chemotherapy to disseminated tumors using nanoparticle-carrying $\mathrm{T}$ cells. Sci Transl Med 7: 291 ra294.

136. Palekar RU, Myerson JW, Schlesinger PH, Sadler JE, Pan H, et al. (2013) Thrombintargeted liposomes establish a sustained localized anticlotting barrier against acute thrombosis. Mol Pharm 10: 4168-4175.

137. DeRosa F, Guild B, Karve S, Smith L, Love K, et al. (2016) Therapeutic efficacy in a hemophilia B model using a biosynthetic mRNA liver depot system. Gene Ther 23: 699-707.

138. Shetty KA, Kosloski MP, Mager DE, Balu-Iyer SV (2016) Factor VIII associated with lipidic nanoparticles retains efficacy in the presence of anti-factor VIII antibodies in hemophilia A mice. Biopharm Drug Dispos 37: 409-420. [Crossref]

139. Shetty KA, Merricks EP, Raymer R, Rigsbee N, Nichols TC, et al. (2016) Soy Phosphatidylinositol-Containing Lipid Nanoparticle Prolongs the Plasma Survival and Hemostatic Efficacy of B-domain-Deleted Recombinant Canine Factor VIII in Hemophilia A Dogs. J Pharm Sci 105: 2459-2464.

140. Schmidt PJ, Toudjarska I, Sendamarai AK, Racie T, Milstein S (2013) Bettencourt $\mathrm{BR}$, et al. An RNAi therapeutic targeting Tmprss6 decreases iron overload in Hfe(/-) mice and ameliorates anemia and iron overload in murine beta-thalassemia intermedia. Blood 121: 1200-1208.

141. Bhushan S, Kakkar V, Pal HC, Mondhe DM, Kaur IP (2016) The augmented anticancer potential of AP9-cd loaded solid lipid nanoparticles in human leukemia Molt-4 cells and experimental tumor. Chem Biol Interact 244: 84-93.

142. Guorgui J, Wang R, Mattheolabakis G, Mackenzie GG (2018) Curcumin formulated in solid lipid nanoparticles has enhanced efficacy in Hodgkin's lymphoma in mice. Arch Biochem Biophys 648: 12-19.

143. Mansilla E, Marin GH, Nunez L, Drago H, Sturla F, et al. (2010) The lysosomotropic agent, hydroxychloroquine, delivered in a biodegradable nanoparticle system, overcomes drug resistance of B-chronic lymphocytic leukemia cells in vitro. Cancer Biother Radiopharm 25: 97-103.

144. Guo L, Zhang H, Wang F, Liu P, Wang Y, et al. (2015) Targeted multidrug-resistance reversal in tumor based on PEG-PLL-PLGA polymer nano drug delivery system. Int J Nanomedicine 10: 4535-4547.

145. Khan I, Gothwal A, Sharma AK, Qayum A, Singh SK, et al. (2016) Biodegradable nano-architectural PEGylated approach for the improved stability and anticancer efficacy of bendamustine. Int J Biol Macromol 92: 1242-1251.

146. Han M, Diao YY, Jiang HL, Ying XY, Chen DW, et al. (2011) Molecular mechanism study of chemosensitization of doxorubicin-resistant human myelogenous leukemia cells induced by a composite polymer micelle. Int J Pharm 420: 404-411.

147. Dai Y, Huang J, Xiang B, Zhu H, He C (2018) Antiproliferative and Apoptosi Triggering Potential of Paclitaxel-Based Targeted-Lipid Nanoparticles with Enhanced Cellular Internalization by Transferrin Receptors-a Study in Leukemia Cells. Nanoscale Res Lett 13: 271.

148. Zhu B, Yu L, Yue Q (2017) Co-delivery of vincristine and quercetin by nanocarriers for lymphoma combination chemotherapy. Biomed Pharmacother 91: 287-294.

149. Qiu L, Dong C, Kan X (2018) Lymphoma-targeted treatment using a folic aciddecorated vincristine-loaded drug delivery system. Drug design, development and therapy 12: 863-872. 
150. Yasinska IM, Ceccone G, Ojea-Jimenez I, Ponti J, Hussain R, et al. (2018) Highly specific targeting of human acute myeloid leukaemia cells using pharmacologically active nanoconjugates. Nanoscale 10: 5827-5833.

151. Simon T, Tomuleasa C, Bojan A, Berindan-Neagoe I, Boca S, et al. (2015) Design of FLT3 Inhibitor - Gold Nanoparticle Conjugates as Potential Therapeutic Agents for the Treatment of Acute Myeloid Leukemia. Nanoscale Res Lett 10: 466.

152. Petrushev B, Boca S, Simon T, Berce C, Frinc I, et al. (2016) Gold nanoparticles enhance the effect of tyrosine kinase inhibitors in acute myeloid leukemia therapy. Int J Nanomedicine 11: 641-660.

153. Suarasan S, Simon T, Boca S, Tomuleasa C, Astilean S (2016) Gelatin-coated Gold Nanoparticles as Carriers of FLT3 Inhibitors for Acute Myeloid Leukemia Treatment. Chem Biol Drug Des 87: 927-935.

154. Goswami U, Dutta A, Raza A, Kandimalla R, Kalita S, et al. (2018) TransferrinCopper Nanocluster-Doxorubicin Nanoparticles as Targeted Theranostic Cancer Nanodrug. ACS Appl Mater Interfaces 10: 3282-3294.

155. Ghaemi B, Mashinchian O, Mousavi T, Karimi R, Kharrazi S, et al. (2016) Harnessing the Cancer Radiation Therapy by Lanthanide-Doped Zinc Oxide Based Theranostic Nanoparticles. ACS Appl Mater Interfaces 8: 3123-3134.

156. Niu F, Yan J, Ma B, Li S, Shao Y, et al. (2018) Lanthanide-doped nanoparticles conjugated with an anti-CD33 antibody and a p53-activating peptide for acute myeloid leukemia therapy. Biomaterials 167: 132-142.

157. Saesoo S, Sathornsumetee S, Anekwiang P, Treetidnipa C, Thuwajit P, et al. (2018) Characterization of liposome-containing SPIONs conjugated with anti-CD20 developed as a novel theranostic agent for central nervous system lymphoma. Colloids Surf B Biointerfaces 161: 497-507.

158. Torino E, Auletta L, Vecchione D, Orlandella FM, Salvatore G, et al. (2018) Multimodal imaging for a theranostic approach in a murine model of B-cell lymphoma with engineered nanoparticles. Nanomedicine 14: 483-491.

159. Barth BM, E IA, Shanmugavelandy SS, Kaiser JM, Crespo-Gonzalez D, et al. (2011) Targeted indocyanine-green-loaded calcium phosphosilicate nanoparticles for in vivo photodynamic therapy of leukemia. ACS Nano 5: 5325-5337.

160. Auerbach M, Pappadakis JA, Bahrain H, Auerbach SA, Ballard H, et al. (2011) Safety and efficacy of rapidly administered (one hour) one gram of low molecular weight iron dextran (INFeD) for the treatment of iron deficient anemia. American Journal of Hematology 86: 860-862.

161. Gabizon A, Martin F (1997) Polyethylene Glycol-Coated (Pegylated) Liposomal Doxorubicin. Drugs 54: 15-21.

162. Gabizon AA, Barenholz Y, Bialer M (1993) Prolongation of the circulation time of doxorubicin encapsulated in liposomes containing a polyethylene glycol-derivatized phospholipid: pharmacokinetic studies in rodents and dogs. Pharm Res 10: 703-708.

163. Anselmo AC, Mitragotri S (2016) Nanoparticles in the clinic. Bioeng Transl Med 1: 10-29. [Crossref]

164. Glantz MJ, Jaeckle KA, Chamberlain MC, Phuphanich S, Recht L, et al. (1999) A randomized controlled trial comparing intrathecal sustained-release cytarabine (DepoCyt) to intrathecal methotrexate in patients with neoplastic meningitis from solid tumors. Clin Cancer Res 5: 394-3402.

165. Glantz MJ, LaFollette S, Jaeckle KA, Shapiro W, Swinnen L, et al. (1999) Randomized trial of a slow-release versus a standard formulation of cytarabine for the intrathecal treatment of lymphomatous meningitis. J Clin Oncol 17: 3110-3116

166. Gotloib L1, Silverberg D, Fudin R, Shostak A (2006) Iron deficiency is a common cause of anemia in chronic kidney disease and can often be corrected with intravenous iron. J Nephrol 19: 161-167. [Crossref]

167. Berniere J, Dehullu JP, Gall O, Murat I (1998) Intravenous iron in the treatment of postoperative anemia in surgery of the spine in infants and adolescents. Rev Chir Orthop Reparatrice Appar Mot 84: 319-322.

168. Dinndorf PA, Gootenberg J, Cohen MH, Keegan P, Pazdur R (2007) FDA drug approval summary: pegaspargase (oncaspar) for the first-line treatment of children with acute lymphoblastic leukemia (ALL). Oncologist 12: 991-998.

169. Coyne DW (2009) Ferumoxytol for treatment of iron deficiency anemia in patient with chronic kidney disease. Expert Opinion on Pharmacotherapy 10: 2563-2568.

170. Kalra PA, Bhandari S (2016) Efficacy and safety of iron isomaltoside (Monofer((®)) in the management of patients with iron deficiency anemia. International journal of nephrology and renovascular disease 9: 53-64.
171. Rodriguez MA, Pytlik R, Kozak T, Chhanabhai M, Gascoyne R, et al. (2009) Vincristine sulfate liposomes injection (Marqibo) in heavily pretreated patients with refractory aggressive non-Hodgkin lymphoma. Cancer 115: 3475-3482.

172. Silverman JA, Deitcher SR. Marqibo ${ }^{\circledR}$ (2013) vincristine sulfate liposome injection improves the pharmacokinetics and pharmacodynamics of vincristine. Cancer Chemotherapy and Pharmacology 71: 555-564.

173. Mikhail AI, Schön S, Simon S, Brown C, Hegbrant JBA, et al. (2019) A prospective observational study of iron isomaltoside in haemodialysis patients with chronic kidney disease treated for iron deficiency (DINO). BMC nephrology 20:13-13.

174. Kulnigg S, Stoinov S, Simanenkov V, Dudar LV, Karnafel W, et al. (2008) A novel intravenous iron formulation for treatment of anemia in inflammatory bowel disease: the ferric carboxymaltose (FERINJECT) randomized controlled trial. Am J Gastroenterol 103: 1182-1192.

175. Lancet JE, Cortes JE, Hogge DE, Tallman MS, Kovacsovics TJ, et al. (2014) Phase 2 trial of CPX-351, a fixed 5:1 molar ratio of cytarabine/daunorubicin, vs cytarabine/ daunorubicin in older adults with untreated AML. Blood 123: 3239-3246.

176. Nikanjam M, Capparelli E, Lancet JE, Kolitz JE, Louie AC, et al. (2016) Enhanced Cytarabine and Daunorubicin Population Pharmacokinetics When Administered As CPX-351: A Novel Liposomal Formulation Not Requiring Dose Reduction for Mild Renal or Hepatic Dysfunction. Blood 128: 3955.

177. Cortes JE, Goldberg SL, Feldman EJ, Rizzeri DA, Hogge DE, et al. (2015) Phase II, multicenter, randomized trial of CPX-351 (cytarabine:daunorubicin) liposome injection versus intensive salvage therapy in adults with first relapse AML. Cancer 121: $234-242$.

178. Piccaluga PP, Visani G, Martinelli G, Isidori A, Malagola M, et al. (2002) Liposoma daunorubicin (DaunoXome) for treatment of relapsed meningeal acute myeloid leukemia. Leukemia 16:1880-1881.

179. Offidani M, Corvatta L, Centurioni R, Leoni F, Malerba L, et al. (2003) High-dose daunorubicin as liposomal compound (Daunoxome) in elderly patients with acute lymphoblastic leukemia. Hematol $J$ 4: 47-53.

180. Fassas A, Anagnostopoulos A (2005) The use of liposomal daunorubicin (DaunoXome) in acute myeloid leukemia. Leuk Lymphoma 46: 795-802.

181. Luminari S, Montanini A, Caballero D, Bologna S, Notter M, et al. (2010) Nonpegylated liposomal doxorubicin (MyocetTM) combination (R-COMP) chemotherapy in elderly patients with diffuse large B-cell lymphoma (DLBCL): results from the phase II EUR018 trial. Ann Oncol 21: 1492-1499.

182. Dell'Olio M, Scalzulli RP, Sanpaolo G, Nobile M, Mantuano FS, et al. (2011) Nonpegylated liposomal doxorubicin (Myocet(R)) in patients with poor-risk aggressive B-cell non-Hodgkin lymphoma. Leuk Lymphoma 52: 1222-1229.

183. Danoch H, Kalechman Y, Albeck M, Longo DL, Sredni B (2015) Sensitizing Band T- cell Lymphoma Cells to Paclitaxel/Abraxane-Induced Death by AS101 via Inhibition of the VLA-4-IL10-Survivin Axis. Molecular Cancer Research 13: 411.

184. Tan YL, Ho HK (2018) Navigating albumin-based nanoparticles through various drug delivery routes. Drug Discovery Today 23: 1108-1114.

185. Donnellan WB, Atallah EL, Asch AS, Patel MR, Charlton J, et al. (2018) A Phase I/II, Open-Label, Multicentre 2-Part Study to Assess the Safety, Tolerability, Pharmacokinetics, and Efficacy of AZD2811 Nanoparticle As Monotherapy or in Combination in Treatment-Naïve or Relapsed/Refractory Acute Myeloid Leukaemia/ Myelodysplastic Syndrome Patients Not Eligible for Intensive Induction Therapy. Blood 132: 4064.

186. Tari Ashizawa A, Ohanian M, Cortes JE (2016) BP1001, a Novel Therapeutic for Chronic Myelogenous Leukemia. Blood 128: 4239.

187. Ohanian M, Ravandi F, Borthakur G, Garcia-Manero G, Andreeff M, et al. (2016) Phase I study of BP1001 (Liposomal Grb2 Antisense) in patients with hematologic malignancies. Journal of Clinical Oncology 34: 7010-7010.

188. Ohanian M, Tari Ashizawa A, Garcia-Manero G, Pemmaraju N, Kadia T, et al. (2018) Liposomal Grb2 antisense oligodeoxynucleotide (BP1001) in patients with refractory or relapsed haematological malignancies: a single-centre, open-label, dose-escalation, phase 1/1b trial. Lancet Haematol 5: e136-136e146. [Crossref]

189. Tolcher AW, Papadopoulos KP, Patnaik A, Rasco DW, Martinez D, et al. (2015) Safety and activity of DCR-MYC, a first-in-class Dicer-substrate small interfering RNA (DsiRNA) targeting MYC, in a phase I study in patients with advanced solid tumors. Journal of Clinical Oncology 33: 11006-11006.

190. Jovanovi KK, Roche-Lestienne C, Ghobrial IM, Facon T (2018) Targeting MYC in multiple myeloma. Leukemia 32: 1295-1306. [Crossref] 
191. Tyagi P, Santos JL (2018) Macromolecule nanotherapeutics: approaches and challenges. Drug Discovery Today 23: 1053-1061.

192. US5858397.pdf

193. US20030219476A1.pdf

194. Adlakha-Hutcheon G, Bally MB, Shew CR, Madden TD (1999) Controlled destabilization of a liposomal drug delivery system enhances mitoxantrone antitumor activity. Nature Biotechnology 17: 775-779.

195. Ueno T, Endo K, Hori K, Ozaki N, Tsuji A, et al. (2014) Assessment of antitumor activity and acute peripheral neuropathy of 1,2-diaminocyclohexane platinum (II)incorporating micelles (NC-4016). International journal of nanomedicine 9: 3005-3012.
196. Tolcher AW, Rodrigueza WV, Rasco DW, Patnaik A, Papadopoulos KP, et al. (2014) A phase 1 study of the BCL2-targeted deoxyribonucleic acid inhibitor (DNAi) PNT2258 in patients with advanced solid tumors. Cancer Chemotherapy and Pharmacology 73: 363-371.

197. Ebrahim AS, Kandouz M, Liddane A, Sabbagh H, Hou Y, et al. (2016) PNT2258, a novel deoxyribonucleic acid inhibitor, induces cell cycle arrest and apoptosis via a distinct mechanism of action: a new class of drug for non-Hodgkin's lymphoma. Oncotarget 7: 42374-42384.

198. Harb WA, Lakhani N, Logsdon A, Steigelman M, Smith-Green H, et al. (2014) The BCL2 Targeted Deoxyribonucleic Acid Inhibitor (DNAi) PNT2258 Is Active in Patients with Relapsed or Refractory Non-Hodgkin's Lymphoma. Blood 124: 1716.

Copyright: (2019 Limongi T. This is an open-access article distributed under the terms of the Creative Commons Attribution License, which permits unrestricted use, distribution, and reproduction in any medium, provided the original author and source are credited. 